\title{
Calcination-Free Liftoff Photolithography of Mixed Dip-Coated Films Consisting of Rare-Earth-Ion- Doped Nanoparticles on Plastic Sheets
}

\author{
Satoshi Watanabe ${ }^{1 *}$, Hiroshi Hyodo ${ }^{1}$, Hirohisa Taguchi ${ }^{2}$, Kohei Soga ${ }^{1}$, \\ Yoshifumi Takanashi ${ }^{1}$ and Mutsuyoshi Matsumoto ${ }^{1}$ \\ ${ }^{1}$ Department of Materials Science and Technology, Tokyo University of Science (Yamazaki 2641, Noda, Chiba 278-8510, Japan) \\ ${ }^{2}$ Department of Information System Technology, Chukyo University (Kaizu-cho Tokodachi 101, Toyota, Aichi 470-0392, Japan)
}

\begin{abstract}
We discuss the calcination-free liftoff photolithography of inorganic phosphor films consisting of two kinds of rare-earth-ion-doped (RE) nanoparticles dip-coated onto plastic sheets. Green and red upconversion luminescence were emitted from the RE-nanoparticles prepared from $\mathrm{Y}_{2} \mathrm{O}_{3}$ nanoparticles doped with $1 \mathrm{~mol} \% \mathrm{Er}^{3+}$ and $0.75 \mathrm{~mol} \% \mathrm{Yb}^{3+}$ (RE-1-nanoparticles) and those doped with $3 \mathrm{~mol} \% \mathrm{Er}^{3+}$ and 7 mol\% $\mathrm{Yb}^{3+}$ (RE-2-nanoparticles), respectively. Near-infrared (NIR) fluorescence was also observed in the RE-1- and RE-2-nanoparticles. The visible transmittance of the RE-nanoparticle films was more than $90 \%$. The intensity ratio of the green to red upconversion luminescence was controlled by adjusting the mixing ratio of the RE-1- and RE-2-nanoparticles. These results indicate that the multicolor-emitting devices can be fabricated easily for applications of flexible inorganic phosphor films to displays, emitting devices, and sensors with long operating lifetimes and resistance to UV light, air, and water.
\end{abstract}

Key words: Rare-earth-ion-doped nanoparticle, upconversion luminescence, near infrared, flexible device, Kelvin probe force microscopy

\section{Introduction}

Two-dimensional nanofabrication has attracted much attention in various fields such as materials, biotechnology, and information technology. Photolithography ${ }^{1-5)}$, electron-beam lithography ${ }^{6-8)}$, soft lithography ${ }^{9-13)}$ and scanning probe force microscopic lithography ${ }^{14-21)}$, categorized as top-down technologies, have been used. Nanostructures in block copolymers ${ }^{22,23)}$, Langmuir-Blodgett(LB) films ${ }^{24-33)}$ and phospholipid monolayers ${ }^{34-37)}$ have been utilized for patterning functional materials using bottom-up processes.

Rare-earth-ion-doped (RE) inorganic phosphor films have attracted much attention for applications in displays, sensors, and emitting devices because of their unique photonics properties, long operating lifetimes compared with organic semiconductors, and good resistance to fading. Upconversion phenomena originate from rare-earth ions doped in low-phonon inorganic materials under stepwise infrared excitations ${ }^{38,39)}$. These phenomena have been used for nanofabrication ${ }^{40)}$ and high-resolution imaging in nonlinear optical fields ${ }^{41}$. In addition, the near-infrared (NIR) fluorescence of the RE phosphor films is utilized for bio- imaging $^{42)}$ and sensing ${ }^{43)}$ because it can transmit through biological samples with low bio-damage. The wavelength of the upconversion luminescence can be controlled by adjusting the species and the concentrations of the doped rare-earth ions. Furthermore, the multicolor-emitting devices of the RE phosphor films can be fabricated easily by mixing two or more kinds of RE-nanoparticles that exhibit blue, green, and red upconversion luminescence ${ }^{44)}$.

Conventional photolithography involving etching processes allows us to fabricate patterned RE-phosphor films using electrophoretic deposition ${ }^{45)}$, screen printing ${ }^{46)}$, the sol-gel method ${ }^{47)}$, and the polyvinyl alcohol slurry method $^{48)}$. Recently, it was reported that soft lithography combined with sol-gel methods allows the direct fabrication of patterned phosphor films with low cost and without light exposure or etching processes ${ }^{49-53)}$. However, the above techniques require calcination processes after the formation of the patterned precursor films, rendering the fabrication of RE-phosphor films on flexible substrates difficult. The fabrication of flexible inorganic phosphor devices is strongly desired in photonics, electronics, and

\footnotetext{
*Correspondence to: Satoshi Watanabe, Department of Materials Science and Technology, Tokyo University of Science, Yamazaki 2641, Noda, Chiba 278-8510, Japan

E-mail: watasato@rs.noda.tus.ac.jp

Accepted May 15, 2012 (recieved for review April 12, 2012)

Journal of Oleo Science ISSN 1345-8957 print / ISSN 1347-3352 online

http://www.jstage.jst.go.jp/browse/jos/ http://mc.manusriptcentral.com/jjocs
} 
biotechnologies, partly because inorganic phosphor films exhibit longer operating times and better fading resistances than organic emitting materials ${ }^{54-56)}$.

We have reported calcination-free and etching-free photolithography for the formation of inorganic phosphor films of RE-nanoparticles on plastic sheets. RE-nanoparticles prepared by calcination of the precursor enabled us to fabricate RE-phosphor films on plastic sheets ${ }^{57)}$. In this article, we discuss mixed RE-nanoparticle films fabricated from green- and red-emitting RE-nanoparticles (abbreviated as RE-1-nanoparticles and RE-2-nanoparticles, respectively) using calcination-free liftoff photolithography to control the emitting colors of the films. The samples are characterized using optical, fluorescence, scanning electron (SEM), atomic force $(\mathrm{AFM})$, and Kelvin probe force $(\mathrm{KPFM}) \mathrm{mi}$ croscopies.

\section{Experimental Section}

\subsection{Materials}

$\mathrm{Y}\left(\mathrm{NO}_{3}\right)_{3}, \mathrm{Er}\left(\mathrm{NO}_{3}\right)_{3} \cdot 5 \mathrm{H}_{2} \mathrm{O}$ and $\mathrm{Yb}\left(\mathrm{NO}_{3}\right)_{3} \cdot 5 \mathrm{H}_{2} \mathrm{O}$ used for the preparation of $\mathrm{RE}$-nanoparticles were purchased from Aldrich. An aqueous solution of urea $\left(10 \mathrm{~mol} \mathrm{~L}^{-1}\right)$ was purchased from Kanto Chemical Corp. Acetone and chloroform, used for cleaning the substrates, were purchased from Wako Pure Chem. Ind., Ltd. The photoresist AZ 1500 and its developer were purchased from MicroChemicals.

\subsection{Preparation of RE-nanoparticles}

Green-emitting RE-1-nanoparticles and red-emitting RE2-nanoparticles were synthesized using the method of Venkatachalam et $\mathrm{al}^{39}$. The precursor solution for the fabrication of RE-1-nanoparticles was prepared by adding $8 \mathrm{mmol}$ $\mathrm{Y}\left(\mathrm{NO}_{3}\right)_{3}, 0.08 \mathrm{mmol} \mathrm{Er}\left(\mathrm{NO}_{3}\right)_{3} \cdot 5 \mathrm{H}_{2} \mathrm{O}$, and $0.08 \mathrm{mmol} \mathrm{Yb}$ $\left(\mathrm{NO}_{3}\right)_{3} \cdot 5 \mathrm{H}_{2} \mathrm{O}$ to $40 \mathrm{~mL}$ of the $10 \mathrm{~mol} \mathrm{~L}^{-1}$ aqueous urea solution. For the fabrication of RE-2-nanoparticles, the precursor solution was prepared by adding $8 \mathrm{mmol} \mathrm{Y}\left(\mathrm{NO}_{3}\right)_{3}$, $0.40 \mathrm{mmol} \mathrm{Er}\left(\mathrm{NO}_{3}\right)_{3} \cdot 5 \mathrm{H}_{2} \mathrm{O}$, and $0.56 \mathrm{mmol} \mathrm{Yb}\left(\mathrm{NO}_{3}\right)_{3} \cdot 5 \mathrm{H}_{2} \mathrm{O}$ to $40 \mathrm{~mL}$ of the $10 \mathrm{~mol} \mathrm{~L}^{-1}$ aqueous urea solution. $10 \mathrm{~mL}$ of water was added to the precursor solutions under stirring. The precursor solutions were kept at $98^{\circ} \mathrm{C}$ in a water bath for $1 \mathrm{~h}$. The precursor powders were washed centrifugally three times with distilled water, dried at $80^{\circ} \mathrm{C}$, and then calcinated at $900^{\circ} \mathrm{C}$ for $30 \mathrm{~min}$. The diameters of the REnanoparticles were estimated to be about $300 \mathrm{~nm}$ by using dynamic light scattering, as shown in the inset of Fig. 1. The diameters were tuned carefully to prevent the desorption of the RE-nanoparticles from the plastic sheets during the ultrasonication process.

\subsection{Cleaning of substrates}

Polyethylene terephthalate(PET) sheets and n-type $\mathrm{Si}$ (a)

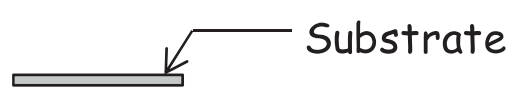

(b)

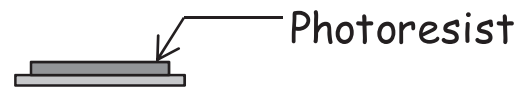

(c)

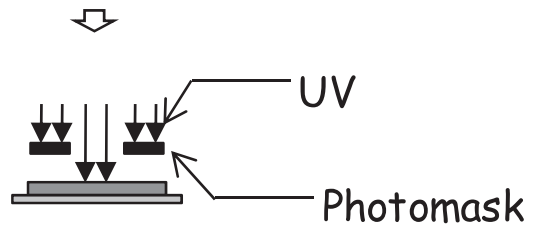

(d)

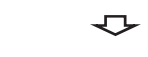

(e)
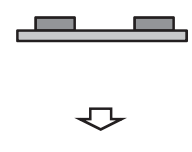

$(f)$

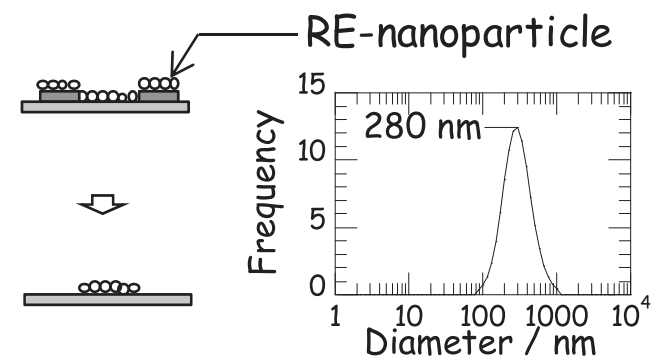

Fig. 1 Fabrication processes of mixed RE-nanoparticle films on plastic sheets using calcination-free liftoff photolithography; (a) cleaning of substrates, (b) spin-coating of photoresist, (c) UV exposure through a photomask, (d) development, (e) dipcoating of RE-nanoparticle films, (f) liftoff procedures. The inset image shows a dynamic light scattering spectrum of RE-nanopartices dispersed in water.

wafers with native oxide (resistivity: $1-10 \Omega \mathrm{cm}$ ) used as the substrates were rinsed with acetone and then chloroform under ultrasonication for $20 \mathrm{~min}$ each. After being dried with nitrogen gas, the substrates were irradiated with UV light from a low-pressure mercury lamp for $15 \mathrm{~min}$ in an ozone atmosphere generated from a PL 16-110 ultraviolet-ozone cleaner(Sen Lights Corp., Japan). The distance between the substrates and the light source was about 5 cm(Fig. 1 (c)) . 


\subsection{Fabrication of patterned RE-nanoparticle films by dip- coating}

After the cleaning of the substrates, a solution of AZ 1500 was spin-coated onto the substrates, first at a rotational speed of $1000 \mathrm{rpm}$ for $10 \mathrm{~s}$, and then at $3000 \mathrm{rpm}$ for $30 \mathrm{~s}$. The photoresist films were kept at $100^{\circ} \mathrm{C}$ for $5 \mathrm{~min}$ in a $\mathrm{N}_{2}$ atmosphere for drying, and then exposed for $7-15 \mathrm{~s}$ to UV light from a 100-W high-pressure Hg lamp through a photomask consisting of a vapor-deposited $\mathrm{Cr}$ film on a quartz plate. Two types of photomasks were used: one with a line pattern with lines/spaces of $15 / 200 \mu \mathrm{m}$, and the other with a pattern of dots of diameter $100 \mu \mathrm{m}$ (Fig. 1(c)). The photoresist films were immersed in the developer solution with shaking for $30 \mathrm{~s}$ and rinsed three times with distilled water, resulting in the formation of patterned photoresist films (Fig. 1(d)). RE-nanoparticles in water $\left(1 \mathrm{mg} \mathrm{mL}^{-1}\right)$ were ultrasonicated for $1 \mathrm{~h}$ at room temperature before use to ensure that they were thoroughly dispersed. REnanoparticles were deposited on the patterned photoresist films using dip-coating at a dipping speed of $5 \mathrm{~mm} \mathrm{~min}^{-1}$ (Fig. 1(e) ). Subsequently, the RE-nanoparticle films were immersed in acetone for $30 \mathrm{~s}$, resulting in the selective removal of the photoresist films and the RE-nanoparticles adsorbed on them (Fig. 1(f)). In the experiment shown in Fig. 2(c), ultrasonication was carried out at an oscillating frequency of $38 \mathrm{kHz}$ at an ultrasonic output power of 180 W using a US-SKS ultrasonic cleaner (SND Co. Ltd., Japan).

\subsection{Characterization}

Visible emission spectra were measured with an RF-5000 visible spectrometer (Shimadzu, Japan). NIR emission spectra were obtained using an NIR spectrometer (AvaSpec, USA) and a semiconductor laser diode operating at $980 \mathrm{~nm}$. Transmission spectra were measured on a V-560 visible spectrometer (JASCO, Japan). Fluorescence and NIR imaging was performed with an IX-71 optical microscope(Olympus, Japan)attached to a band-pass filter at 550 or $650 \mathrm{~nm}$ and a short-pass filter at $900 \mathrm{~nm}$. SEM observations were made with an S-4200 microscope(Hitachi, Japan). AFM and KPFM observations were made using an SPA 300 AFM unit with a Nanonavi controller (SII nanotechnology, Japan). The measurements were performed in non-contact mode using a Au-coated Si tip with a resonance frequency of $27 \mathrm{kHz}$ and a spring constant of $1.7 \mathrm{~N}$ $\mathrm{m}^{-1}$. An AC voltage of $10 \mathrm{~V}$ was applied to the cantilever, which was oscillated at a resonance frequency of $26 \mathrm{kHz}$. (a)

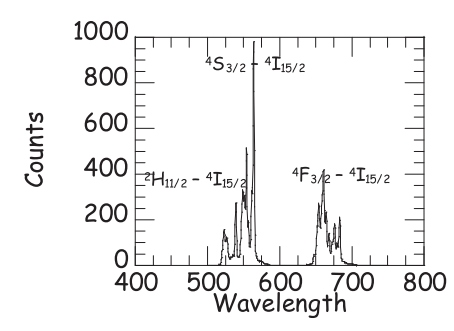

(d)

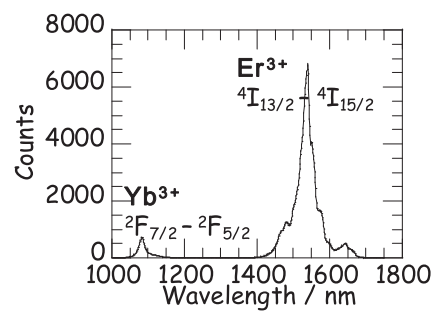

(b)

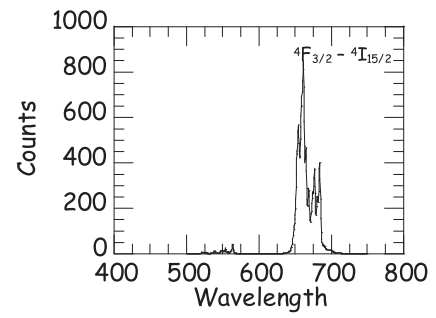

(c)

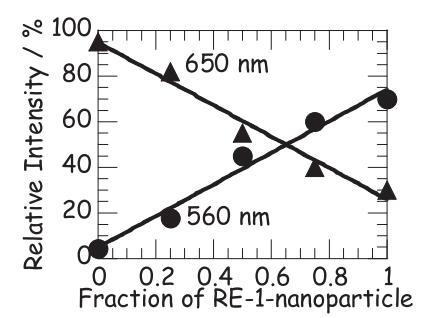

(e)

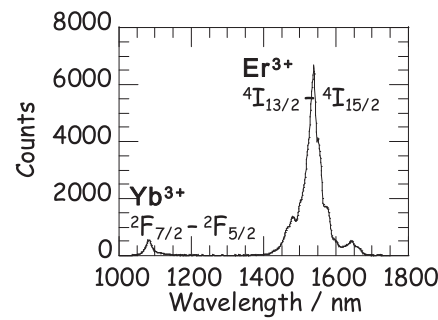

(f)

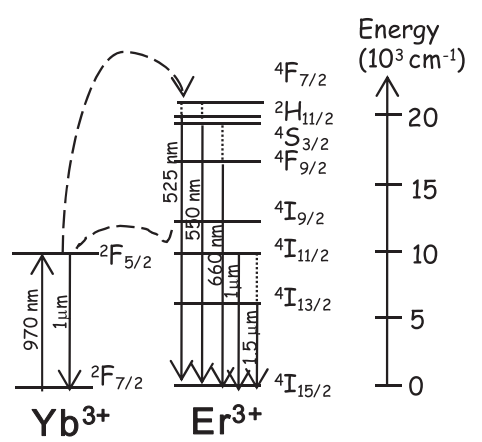

Fig. 2 Visible emission spectra of (a) RE-1-nanoparticles and (b) RE-2-nanoparticles under NIR excitation. (c) Relative emission intensity of the mixtures of RE-1- and RE-2-nanoparticles as a function of fraction of RE1-nanoparticle. NIR spectra of (d) RE-1-nanoparticles and (e) RE-2-nanoparticles. (f) Energy-level diagram of $\mathrm{Yb}^{3+}$ and $\mathrm{Er}^{3+}$ systems. Full, doted and dashed downward arrows show radiative processes, multiphonon relaxations and energy transfers, respectively. 


\section{S. Watanabe, H. Hyodo, H. Taguchi et al.}

\section{Results and Discussion}

\subsection{Optical properties of RE-nanoparticles}

Visible upconversion luminescence occurs from low-phonon inorganic materials doped with rare-earth ions on the basis of two-step NIR excitation. The emitting colors of the materials can be controlled easily by adjusting the mixing ratio of two or more types of RE-nanoparticles. We investigated the upconversion luminescence and NIR fluorescence of the RE-1-and RE-2-nanoparticle powders and their mixtures.

Figure 2 (a) shows the upconversion luminescence spectrum of the RE-1-nanoparticles. The upconversion luminescence peaks at 525 and $560 \mathrm{~nm}$ are attributed to the ${ }^{2} \mathrm{H}_{11 / 2}-{ }^{4} \mathrm{I}_{15 / 2}$ and ${ }^{4} \mathrm{~S}_{3 / 2}-{ }^{4} \mathrm{I}_{15 / 2}$ transitions of $\mathrm{Er}^{3+}$, respectively. The upconversion luminescence at $660 \mathrm{~nm}$ is assigned to the ${ }^{4} \mathrm{~F}_{9 / 2}-{ }^{4} \mathrm{I}_{15 / 2}$ transition. The green upconversion luminescence of the RE-1-nanoparticles is larger than the red luminescence, indicating that the RE-1-nanoparticles serve as green-emitting fluorescent nanoparticles. Figure 2(b) shows the upconversion luminescence spectrum of the RE2-nanoparticles. The upconversion luminescence appears only at $660 \mathrm{~nm}$, indicating that the RE-2-nanoparticles serve as red-emitting fluorescent nanoparticles. Figure 2 (c) shows the relative upconversion intensity of the mixture of the two types of particles as a function of the fraction of the RE-1-nanoparticle. An increase in the fraction of RE-1-nanoparticles leads to a linear increase in the relative intensity of the green upconversion luminescence and a linear decrease in the relative intensity of the red upconversion luminescence. These results indicate that the adjustment of the fraction of RE-nanoparticles allows for the control of the upconversion intensity ratio of $\mathrm{RE}$ nanoparticle mixtures.

Parts (d) and (e) of Fig. 2 show the NIR fluorescence spectra of the RE-1- and RE-2-nanoparticles, respectively. The NIR fluorescence peaks at 1100 and $1500 \mathrm{~nm}$ are attributed to the ${ }^{2} \mathrm{~F}_{5 / 2}-{ }^{2} \mathrm{~F}_{7 / 2}$ transition of $\mathrm{Yb}^{3+}$ and the ${ }^{4} \mathrm{I}_{13 / 2}-$ ${ }^{4} \mathrm{I}_{15 / 2}$ transition of $\mathrm{Er}^{3+}$, respectively. The intensity of the NIR fluorescence at $1500 \mathrm{~nm}$ is larger than that at $1100 \mathrm{~nm}$ owing to energy transfer from the excited $\mathrm{Yb}^{3+}$ to $\mathrm{Er}^{3+}$. These results indicate that the RE-nanoparticles serve as NIR-emitting nanoparticles.

Figure 2(f) shows the energy-level diagram corresponding to this mechanism ${ }^{58,59)}$. The absorption of an NIR photon by $\mathrm{Yb}^{3+}$ and subsequent energy transfer from the excited ${ }^{2} \mathrm{~F}_{5 / 2}$ level of $\mathrm{Yb}^{3+}$ to $\mathrm{Er}^{3+}$ promote $\mathrm{Er}^{3+}$ to the quasi-resonant metastable ${ }^{4} \mathrm{I}_{11 / 2}$ level. The absorption of a second NIR photon by $\mathrm{Yb}^{3+}$ and subsequent energy transfer from this excited ${ }^{2} \mathrm{~F}_{5 / 2}$ level of $\mathrm{Yb}^{3+}$ to the previously excited ${ }^{4} \mathrm{I}_{11 / 2}$ level of $\mathrm{Er}^{3+}$ promote $\mathrm{Er}^{3+}$ to the ${ }^{4} \mathrm{~F}_{7 / 2}$ level. The two main emission lines centered at 525 and $560 \mathrm{~nm}$ correspond to the radiative ${ }^{2} \mathrm{H}_{11 / 2}-{ }^{4} \mathrm{I}_{15 / 2}$ and ${ }^{4} \mathrm{~S}_{3 / 2}-{ }^{4} \mathrm{I}_{15 / 2}$ transitions of $\mathrm{Er}^{3+}$, respectively. The red emission peak at 660 $\mathrm{nm}$ arises from the ${ }^{4} \mathrm{~F}_{9 / 2}-{ }^{4} \mathrm{I}_{15 / 2}$ transition.
High transmittance of the devices is required for applications in flexible displays, flexible sensors, and flexible lightemitting devices. We investigated the visible transmittances of the patterned RE-1-nannoparticle films on PET sheets.

Figure 3(a) shows a photograph of the RE-1-nanoparticle film dip-coated on a PET sheet. Figure 3(b) shows a visible transmittance spectrum of the RE-1-nanoparticle film measured in the region indicated by the arrow in Fig. 3 (a). The transmittance is more than $90 \%$ in the visible region, and is comparable to that of the RE-phosphor films fabricated by the combination of a sol-gel process and soft lithography ${ }^{49,51)}$. For the investigation of their stability, the RE-1-nanoparticle films were immersed in acetone for 60 min, and then ultrasonicated for a subsequent $60 \mathrm{~min}$. Figure $3(\mathrm{c})$ shows the relative transmittance of the RE1-nanoparticle films at $530 \mathrm{~nm}$ as a function of immersion time. The relative transmittance means the transmittance of the RE-1-nanoparticle film normalized to that of the asfabricated RE-1-nanoparticle film. The relative transmittance of the RE-1-nanoparticle film remains unchanged during immersion in acetone at room temperature. The immersion of the RE-1-nanoparticle films in hexane and chloroform gave similar results. Subsequent ultrasonication in acetone drastically decreases the relative transmittance of the RE-1-nanoparticle film, which is caused by the desorption of RE-1-nanoparticles from the RE-1-nanoparticle film. This indicates that the RE-1-nanoparticles are physically adsorbed onto PET sheets as well as onto glass plates ${ }^{57)}$. These results show that the RE-1-nanoparticle films have good transmittance in the visible light range. In addition, the RE-nanoparticle films are stable under immersion in organic solvents at room temperature. This feature is indispensable for the modification of RE-nanoparticle surfaces with silane-coupling agents.

\subsection{Liftoff photolithography of mixed RE-nanoparticle films}

Conventional photolithography enables us to fabricate patterned inorganic phosphor films ${ }^{45-48)}$. However, this technique requires calcination processes, so it is difficult to fabricate patterned inorganic phosphor films on flexible substrates. In addition, this technique suffers from the problem of material consumption, because etching processes are necessary for the formation of patterned inorganic phosphor films. We have demonstrated that calcination and etching-free photolithography enables the fabrication of patterned inorganic phosphor films consisting of RE-nanoparticles, not only on inorganic substrates, but also on flexible ones ${ }^{57)}$. The results in Fig. 2 (c) show that the intensity ratio of the green to red upconversion luminescence from the mixtures of RE-1- and RE-2-nanoparticles can be controlled. We fabricated patterned mixed REnanoparticle films on PET sheets.

Figure 4 shows (a) optical microscopic, (b) upconversion 
(a)

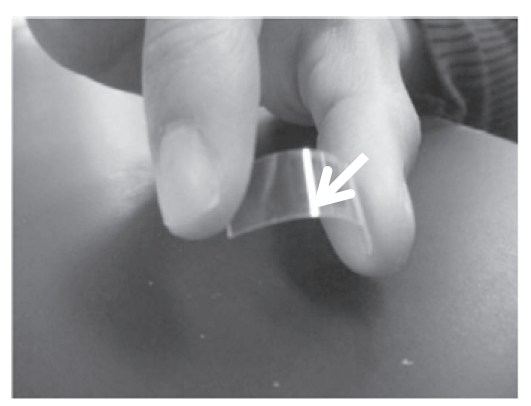

(b)

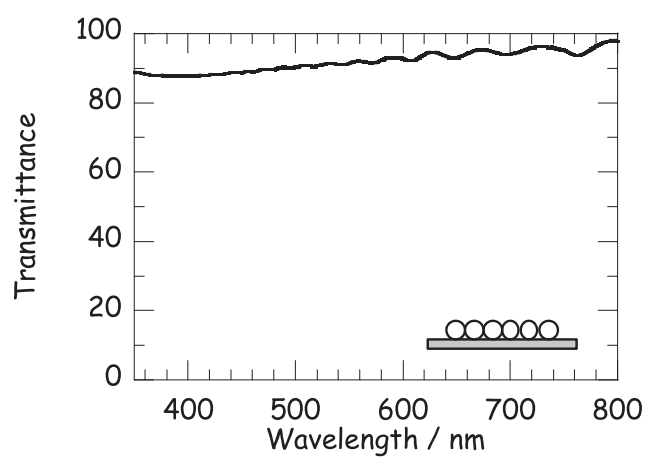

(c)

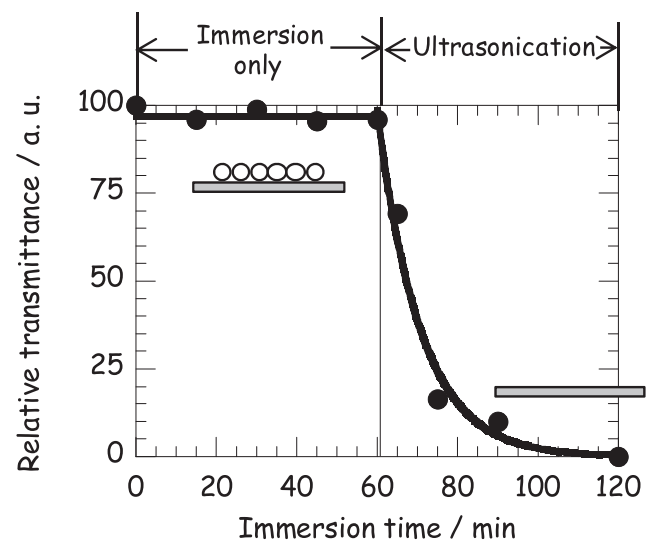

Fig. 3 (a) Photograph and (b) visible transmission spectrum of a RE-1-nanoparticle film dip-coated on a PET sheet. The visible transmittance measurement was carried out in the region of the RE-1-nanoparticle film shown by the arrow in Fig. 3 (a). (c) Relative transmittance of the RE1-nanoparticle film at $530 \mathrm{~nm}$ as a function of immersion time. The RE-1-nanoparticle film was immersed in acetone for $60 \mathrm{~min}$, followed by ultrasonication in acetone for a subsequent $60 \mathrm{~min}$. (a)

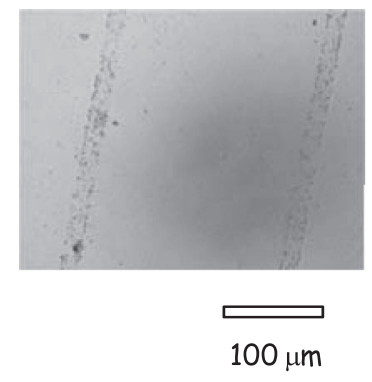

(b)

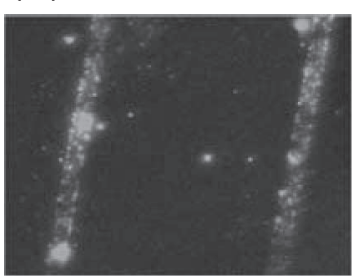

$\stackrel{\square}{\square}$

(c)

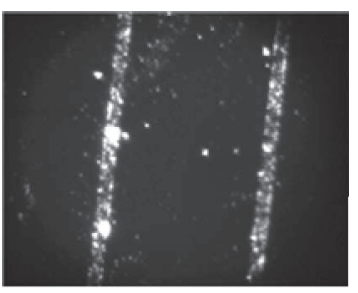

$\Longleftarrow 100 \mu \mathrm{m}$ (d)

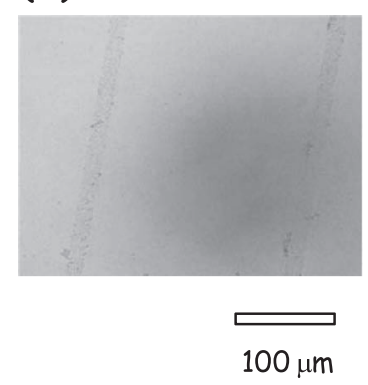

(e)

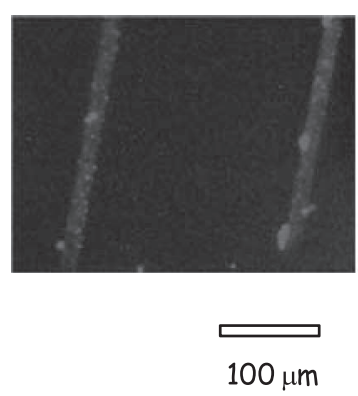

(f)

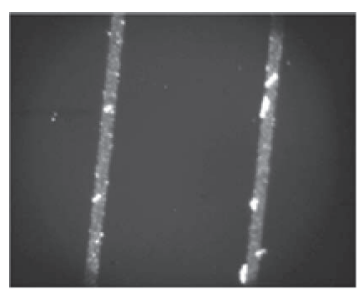

ए $100 \mathrm{~m}$
Fig. 4 (a) Optical microscopic, (b) upconversion luminescence and (c) NIR fluorescence images of a patterned RE-1-nanoparticle film dip-coated on a PET sheet under NIR excitation. (d) Optical microscopic, (e) upconversion luminescence and (f) NIR fluorescence images of a patterned RE2-nanoparticle film dip-coated on a PET sheet.

luminescence, and (c) NIR fluorescence images of a patterned RE-1-nanoparticle film on a PET sheet. RE1-nanoparticle films patterned with lines are formed. The widths of the lines and spaces are about 20 and $150 \mu \mathrm{m}$, respectively. The green upconversion and the NIR luminescence are evident from the line-patterned RE-1-nanoparticle film. Figure 4 shows (d) optical microscopic, (e) upconversion luminescence at $650 \mathrm{~nm}$, and (f) NIR fluorescence images of an RE-2-nanoparticle film fabricated on a PET sheet. The widths of the lines and spaces of the patterned 
RE-2-nanoparticle film are about 20 and $150 \mu \mathrm{m}$, respectively. Upconversion luminescence at $660 \mathrm{~nm}$ emitted from $\mathrm{Er}^{3+}$ in the RE-2-nanoparticles and NIR fluorescence at 1100 and $1600 \mathrm{~nm}$ from $\mathrm{Yb}^{3+}$ and $\mathrm{Er}^{3+}$ in the RE2-nanoparticles are also seen. These results indicate that green- and red-emitting inorganic phosphor films can be fabricated on PET sheets.

Figure 5 (a) shows optical microscopic images of patterned mixed RE-nanoparticle films on PET sheets (RE1-nanoparticles/RE-2-nanoparticles $=75 / 25,50 / 50$ and $25 / 75$ wt $\%$ ). The mixed RE-nanoparticle films were formed with dot structures (diameter $\approx 150 \mu \mathrm{m}$ ). Figure 5 (b) shows upconversion luminescence images taken at $550 \mathrm{~nm}$ of the patterned mixed RE-nanoparticle films on PET sheets (RE-1-nanoparticles/RE-2-nanoparticles $=75 / 25$, 50/50, and 25/75 wt\%). Green upconversion luminescence is emitted from the dot-patterned mixed RE-nanoparticle films. With an increase in the fraction of RE-1-nanoparticles, the upconversion luminescence at $550 \mathrm{~nm}$ increases, which is consistent with the results shown in Fig. 2 (c).

Mixing ratio of RE-1- to RE-2-nanoparticles (wt\%) (a)

$75 / 25$

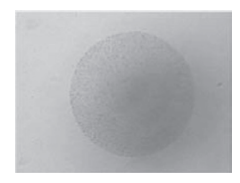

(b)

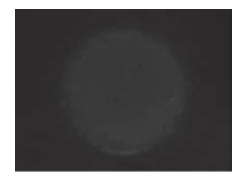

(c)

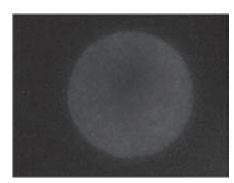

(d)

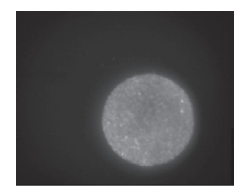

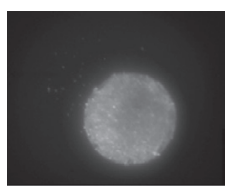

$25 / 75$
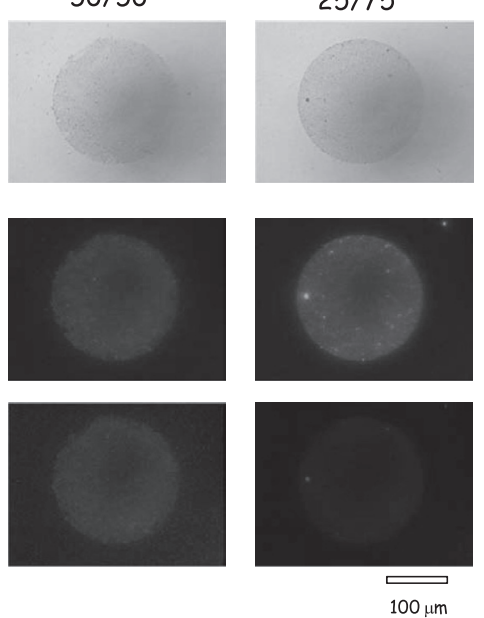

$100 \mu \mathrm{m}$

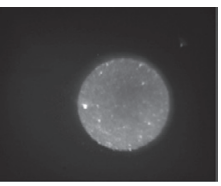

$\widetilde{\Gamma \mu 0 m}$
Fig. 5 (a) Optical microscopic, (b) green upconversion luminescence, (c) red upconversion and (d) NIR luminescence images of mixed RE-nanoparticle films dip-coated on PET sheets under NIR excitation (RE-1-nanoparticles/RE-2-nanoparticles $=75 / 25,50 / 50$ and 25/75 wt $\%$ ). Upconversion luminescence images were obtained using bandpass filters at (b) $550 \pm 20 \mathrm{~nm}$ or (c) $650 \pm 20$ nm.
Figure 5 (c) shows upconversion luminescence images taken at $650 \mathrm{~nm}$ of the mixed RE-nanoparticle films on PET sheets. The upconversion luminescence at $650 \mathrm{~nm}$ is emitted from the dot-patterned mixed RE-nanoparticle films. The luminescence intensity also decreases with an increase in the fraction of RE-2-nanoparticles. Figure 5(d) shows NIR fluorescence images of the patterned REnanoparticle films of the RE-1- and the RE-2-nanoparticles on PET sheets. NIR luminescence is emitted from the mixed RE-nanoparticle films. The intensity of the NIR luminescence is almost constant in the RE-nanoparticle films. These results demonstrate that we successfully obtained patterned mixed RE-nanoparticle films consisting of RE-1- and RE-2-nanoparticles on PET sheets, allowing for the control of the emitting color of the RE-phosphor films.

KPFM provides information on the local work functions of metals ${ }^{60)}$ and organic semiconductors ${ }^{61,62)}$. We investigated the patterned RE-1-nanoparticle films on Si wafers using AFM and KPFM to study the local material distribution of the films.

Figure 6 (a) shows SEM and magnified SEM images of a patterned RE-1-nanoparticle film on a Si wafer. The widths of the lines and spaces are about 20 and $150 \mu \mathrm{m}$, respectively. These results are almost coincident with those of the patterned RE-1-nanoparticle film on a PET sheet shown in Fig. 4. Parts (b) and (c) of Fig. 6 show an AFM image and its cross-sectional view, respectively, of the patterned RE1-nanoparticle film on the Si wafer. The thickness of the patterned RE-1-nanoparticle film is about $250 \mathrm{~nm}$. This suggests that the patterned RE-1-nanoparticle film is a particulate monolayer of RE-1-nanoparticles, considering that the diameter of the RE-1-nanoparticles estimated by dynamic light scattering is about $280 \mathrm{~nm}$. The thickness of the stacked RE-1-nanoparticle film was about $500 \mathrm{~nm}$, indicating the formation of particulate bilayers of RE1-nanoparticles. Parts (d) and (e) of Fig. 6 show a KPFM image and its profile, respectively, of the patterned RE1-nanoparticle film. The surface potential of the Si wafer is $1.5 \mathrm{~V}$ lower than that of the patterned monolayer of RE1-nanoparticles. The surface potential reflects the work function of a material. The work functions of the $\mathrm{Y}_{2} \mathrm{O}_{3}$ matrix in the RE-1-nanoparticles and the $\mathrm{SiO}_{2}$ of the $\mathrm{Si}$ wafer are about $2.0^{63)}$ and $3.0-3.4 \mathrm{eV}^{64)}$, respectively. The difference between the surface potentials in the two regions is consistent with that between the work functions of the two materials. In addition, the surface potential of the monolayer is equal to that of the bilayers of RE1-nanoparticles. These results indicate that patterned RE1-nanoparticle films are formed on Si wafers using calcination-free liftoff photolithography. 
(a)

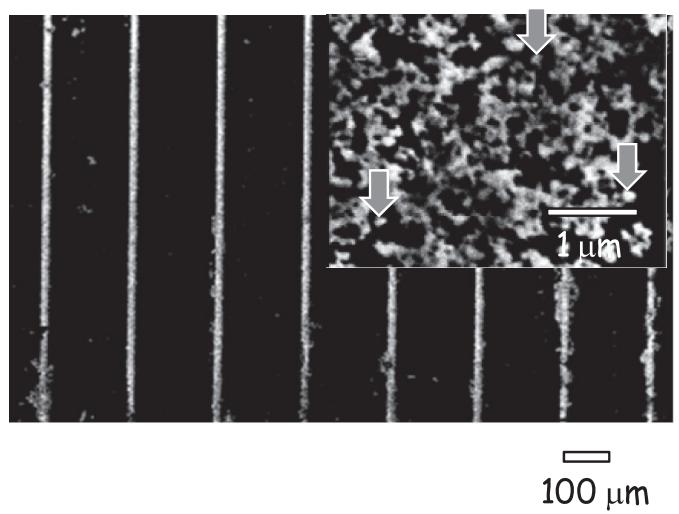

(b)

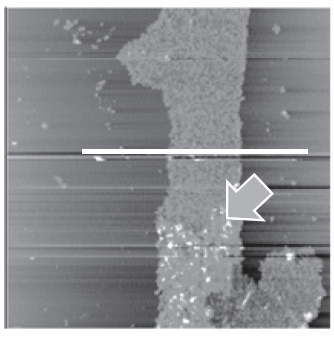

$20 \mu \mathrm{m}$

(c)

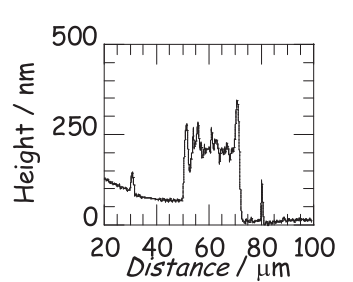

(e)

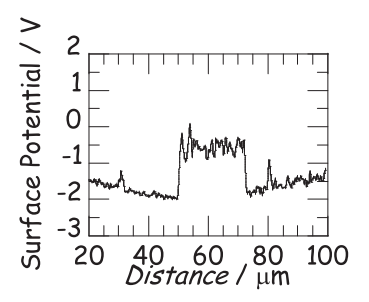

Fig. 6 (a) SEM image and its magnified image (inset), (b) AFM image, (c) its cross-sectional view, (d) surface potential image and (e) its profile of a RE-1-nanoparticle film dip-coated on a Si wafer. The arrows in part (a) show individual RE1-nanoparticles. The arrow in part (b) represents two layers of the RE-1-nanoparticles.

\section{Conclusion}

We have demonstrated that calcination-free photolithography enables the fabrication of inorganic phosphor films consisting of RE-nanoparticles, not only on inorganic substrates, but also on flexible ones ${ }^{57)}$. In this study, we fabricated patterned RE-nanoparticle films consisting of RE-1and RE-2-nanoparticles, and controlled the emitting colors of the films. The visible transparency of the RE-nanoparticle films was more than $90 \%$, which is almost coincident with that of the RE-phosphor films fabricated by other methods ${ }^{49,51)}$. The emission spectra revealed that the intensity ratio of the green to red upconversion luminescence is controllable through adjustment of the mixing ratio of the RE-1- and RE-2-nanoparticles.

To our knowledge, this technique is the only one available for the fabrication of inorganic phosphor films on plastic sheets, enabling the creation of inorganic flexible devices with long operating lifetimes and good resistances to harsh conditions such as exposure to UV light, air, and water. In addition, multicolor-emitting devices and displays can be fabricated easily by adjusting the fractions of blueemitting, green-emitting, and red-emitting RE-nanoparticles. After the liftoff process, the RE-nanoparticles are easily recovered from the developer solutions by centrifugation, thus providing a low-cost method with low material consumption. This technique enables the fabrication of patterned inorganic functional materials consisting of various nanoparticles, and may lead to future applications in flexible inorganic devices.

\section{Acknowledgment}

This work was partly supported by Futaba Electronics Memorial Foundation.

\section{Reference}

1) Horiuchi, S.; Fujita, T.; Hayakawa, T.; Nakao, Y.; Adv. Mater., 15, 1449 (2003).

2) Öner, D.; McCarthy, T. J. Langmuir, 16, 7777 (2000).

3) Levenson, M. D.; Viswanathan, N. S.; Simpson, R. A. IEEE Trans. Electron. Dev. 29, 1828(1982).

4) Jager, E. W. H.; Smela, E.; Inganäs, O. Science, 290, $1540(2000)$.

5) Blawas, A. S.; Reichert, W. M. Biomaterials, 19, 595 (1998).

6) Myers, B. D.; Dravid, C. P. Nano Lett., 6, 963 (2006).

7) Martin, J. I.; Nogues, J.; Liu, K.; Vicent, J. L.; Schuller, I. K. J. Magn. Magn. Mater. 256, 449 (2003).

8) Chang, T. H. P. J. Vac. Sci. Technol, 12, 1271(1975).

9) Kumar, A.; Biebuyck, H. A.; Whitesides, G. M. Langmuir, 10, 1498(1994).

10) Xia, Y.; Whitesides, G. M. Annu. Rev. Mater. Sci., 28, 153 (1998).

11) Unger, M. A.; Chou, H.; Thorsen, T.; Scherer, A.; Quake, S. R. Science, 288, 113(2000).

12) Whitesides, G. M.; Ostuni, E.; Takayama, S.; Jiang, X.; Ingber, D. E. Annu. Rev. Biomed. Eng. 3, 335 (2001).

13) Cavallini, M.; Albonetti, C.; Biscarini, F. Adv. Mater. 21, 1043(2009).

14) Piner, R. D.; Zhu, J.; Xu, F.; Hong, S.; Mirkin, C. A. Science, 283, 661 (1999). 
15) Ginger, D. S.; Zhang, H.; Mirkin, C. A. Angew. Chem. Int. Ed., 43, 30 (2004).

16) Salaita, K.; Wang, Y.; Mirkin, C. A. Nature Nanotech., 2, 145(2007).

17) Li, Y.; Maynor, B. W.; Liu, J. J. Am. Chem. Soc., 123, 2105 (2001).

18) Krämer, S.; Fuierer, R. R.; Gorman, C. B. Chem. Rev., 103, 4367 (2003).

19) Naber, A.; Kock, H.; Fuchs, H. Scanning, 18, 567 (1996).

20) Alkaisi, M. M.; Blaikie, R. J.; McNab, S. J.; Cheung, R.; Cumming, D. R. S. Appl. Phys. Lett., 75, 3560 (1999).

21) Sun, S.; Leggett, G. J. Nano Lett., 4, 1381 (2004).

22) Lopes, W. A.; Jaeger, H. M. Nature, 414, 735 (2001).

23) Tang, C.; Lennon, E. M.; Fredrickson, G. H.; Kramer, E. J.; Hawker, C. J. Science, 322, 429 (2008).

24) Matsumoto, M.; Watanabe, S.; Tanaka, K.; Kimura, H.; Kasahara, M.; Shibata, H.; Azumi, R.; Sakai, H.; Abe, M.; Kondo, Y.; Yoshino, N. Adv. Mater., 19, 3668 (2007)

25) Watanabe, S.; Kimura, H.; Sato, T.; Shibata, H.; Sakamoto, F.; Azumi, R.; Sakai, H.; Abe, M.; Matsumoto, M. Langmuir, 24, 8735 (2008).

26) Watanabe, S.; Shibata, H.; Sakamoto, F.; Azumi, R.; Sakai, H.; Abe, M. J. Mater. Chem., 19, 6796 (2009).

27) Watanabe, S.; Shibata, H.; Horiuchi, H.; Azumi, R.; Sakai, H.; Abe, M.; Matsumoto, M. J. Colloid Interface Sci., 343, 324(2010).

28) Matsumoto, M.; Tanaka, K.; Azumi, R.; Kondo, Y.; Yoshino, N. Langmuir, 20, 8728(2004).

29) Shibata, H.; Sato, M.; Watanabe, S.; Matsumoto, M. Colloid Surface A, 346, 58(2009).

30) Mori, T.; Sakakibara, K.; Endo, H.; Akada, M.; Okamoto, K.; Shundo, A.; Lee, M. V.; Ji, Q.; Fujisawa, T.; Oka, K.; Matsumoto, M.; Sakai, H.; Abe, M.; Hill, J. P.; Ariga K. Chem. Lett. 41, 170 (2012).

31) Ariga, K.; Mori, T.; Hill J. P. Adv. Mater. 24, 158(2012).

32) Sakakibara, K.; Hill, J. P.; Ariga, K. Small 7, 1288 (2011)

33) Krishnan, V.; Sakakibara, K.; Mori, T.; Hill, J. P.; Ariga, K. Curr. Opin. Colloid Interface Sci. 16, 459 (2010)

34) Gleiche, M.; Chi, L. F.; Fuchs, H. Nature, 403, 173 (2000).

35) Purrucker, O.; Förtig, A.; Lüdtke, K.; Jordan, R.; Tanaka, M. J. Am. Chem. Soc., 127, 1258(2005).

36) Lu, N.; Gleiche, M.; Zheng, J.; Lenhert, S.; Xu, B.; Chi, L.; Fuchs, H. Adv. Mater., 14, 1812 (2002).

37) Lu, N.; Chen, X.; Molenda, D.; Naber, A.; Fuchs, H.; Talapin, D. V.; Weller, H.; Muller, J.; Lupton, J. M.; Feldmann, J.; Rogach, A. L.; Chi, L. Nano Lett., 4, 885 (2004).

38) Mialon, G.; Türkcan, S.; Dantelle, G.; Collins, D. P.; Hadjipanayi, M.; Taylor, R. A.; Gacoin, T.; Alexandrou, A.; Boilot, J. P. J. Phys. Chem. C, 114, 22449 (2010).
39) Venkatachalam, N.; Saito, Y.; Soga, K. J. Am. Ceram. Soc., 92, 1006 (2009).

40) Cumpston, B. H.; Ananthavel, S. P.; Barlow, S.; Dyer, D. L.; Ehrlich, J. E.; Erskine, L. L.; Heikal, A. A.; Kuebler, S. M.; SandyLee, I. Y.; McCord-Maughon, D.; Qin, J.; Röckel, H.; Rumi, M.; Wu, X.; Marder, S. R.; Perry, J. W. Nature, 398, 51 (1999).

41) Miller, M. J.; Wei, S. H.; Parker, I.; Cahalan, M. D. Science, 296, 1869 (2002).

42) Konishi, T.; Yamada, M.; Soga, K.; Matsuura, D.; Nagasaki, Y. J. Photopolym. Sci. Technol., 19, 145(2006).

43) Eliseeva, S. V.; Bünzli, J. G. Chem. Soc. Rev., 39, 189 (2010).

44) Matsuura, D. Appl. Phys. Lett., 81, 4526 (2002).

45) Sluzky, E.; Hesse, K. J. Electrochem. Soc., 126, 2742 (1989).

46) Holmes, P. J.; Loasby, R. G. in Handbook of Thick Film Technology, Electrochemical Publications, Ayr, UK, p $50(1976)$.

47) Jang, J. E.; Gwak, J. H.; Jin, Y. W.; Lee, S. J.; Park, H.; Jung, J. E.; Lee, N. S. J. Vac. Sci. Technol. B, 18, 1106 (2000).

48) Jin, Y. W.; Jang, J. E.; Yi, W. K.; Jung, J. E.; Lee, N. S.; Kim, J. M.; Jun, D. Y.; Hong, J. P.; J. Vac. Sci. Technol. $B, 17,489$ (1999).

49) Yu, M.; Lin, J.; Wang, Z.; Fu, J.; Wang, S.; Zhang, H. J.; Han, Y. C. Chem. Mater. 14, 2224 (2002).

50) Yu, M.; Lin, J.; Fu, J.; Zhang, H. J.; Han, Y. C. J. Mater. Chem., 13, 1413(2003).

51) Wang, W.; Cheng, Z.; Yang, P.; Hou, Z.; Li, C.; Li, G.; Dai, Y.; Lin, J. Adv. Funct. Mater., 21, 456 (2011).

52) Pang, M. L.; Lin, J.; Cheng, Z. Y.; Fu, J.; Xing, R. B.; Wang, S. B. Mater. Sci. Eng. B, 100, 124(2003).

53) Pang, M. L.; Lin, J.; Fu, J.; Xing, R. B.; Luo, C. X.; Han, Y. C. Opt. Mater., 23, 547 (2003).

54) Zhang, S.; Shen, Y.; Fang, H.; Xu, S.; Song, J.; Wang, Z. L. J. Mater. Chem., 20, 10606 (2010).

55) Ribierre, J. C.; Fujiwara, T.; Watanabe, S.; Matsumoto, M.; Muto, T.; Nakao, A.; Aoyama, T. Adv. Mater., 22, 1 (2010).

56) Forrest, S. R. Nature, 428, 911(2004).

57) Watanabe, S.; Hyodo, H.; Taguchi, H.; Soga, K.; Takanashi, Y.; Matsumoto, M. Adv. Funct. Mater., 21, 4246 (2011).

58) Gamelin, D. R.; Güdel, H. U. Top. Curr. Chem., 214, 1 (2001)

59) Auzel, F. Chem. Rev., 104, 139 (2004).

60) Palermo, V.; Palma, M.; Samori, P. Adv. Mater., 18, 145 (2006).

61) Hoppe, H.; Glatzel, T.; Niggemann, M.; Hinsch, A.; LuxSteiner, M. C.; Sariciftci, N. S. Nano Lett., 5, 269 (2005).

62) Watanabe, S.; Aoyama, T.; Fukuchi, Y.; Yamashita, T.; Matsumoto, M.; Wada, T. J. Photopolym. Sci. Tech- 
nol., 22, 571(2009).

63) Koumoto, K.; Seo, W. S.; Ozawa, S. Appl. Phys. Lett., 71, 1475(1997).
64) Romero, H. E.; Shen, H.; Joshi, P.; Gutierrez, H. R.; Tadigadapa, S. A.; Sofo, J. O.; Eklund, P. C. ACS Nano, 2, 2037 (2008). 